Article

\title{
Applying Analytic Hierarchy Process to Adaptation to Saltwater Intrusion in Vietnam
}

\author{
Thi Dieu Linh Nguyen ${ }^{1,2, *(D)}$ and Brent Bleys ${ }^{2}$ (D) \\ 1 Faculty of Business and Administration, University of Economics, Hue University, Ho Dac Di 99, \\ 52000 Hue, Vietnam \\ 2 Department of Economics, Ghent University, Tweekerkenstraat 2, 9000 Ghent, Belgium; Brent.Bleys@Ugent.be \\ * Correspondence: ntdlinh.hce@hueuni.edu.vn; Tel.: +84-905-146-869
}

check for updates

Citation: Nguyen, T.D.L.; Bleys, B. Applying Analytic Hierarchy Process to Adaptation to Saltwater Intrusion in Vietnam. Sustainability 2021, 13, 2311. https://doi.org/10.3390/ su13042311

Academic Editor: Aitazaz

A. Farooque

Received: 30 November 2020

Accepted: 8 February 2021

Published: 20 February 2021

Publisher's Note: MDPI stays neutral with regard to jurisdictional claims in published maps and institutional affiliations.

Copyright: (c) 2021 by the authors. Licensee MDPI, Basel, Switzerland. This article is an open access article distributed under the terms and conditions of the Creative Commons Attribution (CC BY) license (https:/ / creativecommons.org/licenses/by/ $4.0 /)$.

\begin{abstract}
Given the multidimensional nature of climate change issues, decision-making in climate change adaptation is a complex process, and suitable decision support methods are needed. The aim of this paper was to rank saltwater intrusion adaptation options for farmers in two provinces in the central coastal region of Vietnam using the analytical hierarchy process method. Data for the analysis were obtained through a literature review, field observations, and face-to-face interviews and focus group discussions with key informants. We combined two ways of weighting to arrive at final scores for each of the identified adaptation options: prioritizing criteria and subcriteria by pairwise comparison and rating the different alternatives with respect to the lowest level subcriteria. In doing so, we also investigated differences in the priority sets and final rankings of the analytical hierarchy process applications in both provinces. In our study, we worked with group consensus scores on both the criteria weights and the ratings for the different adaptation options for each of the criteria. Our results revealed that "sustainability and equity" was the most important criteria, while coherence ranked lowest. The final ranking of adaptation options differed between both provinces due to differences in the geographical and socioeconomic characteristics of the study areas. The consistency ratios for all pairwise matrices were less than 0.1 , indicating that judgments from the focus group discussions with respect to the different criteria were highly consistent. A sensitivity analysis of our results confirmed the robustness of the rankings in our research.
\end{abstract}

Keywords: climate change; analytic hierarchy process; saltwater intrusion

\section{Introduction}

The last five years have been the warmest on record, and climate change is expected to strike harder in the coming years with extreme weather events predicted to become both more frequent and more intense. As a result, global risk perceptions are shifting as the biggest threats to mankind are no longer related to economic problems, but to climate action failure, natural disasters, biodiversity losses, and extreme weather events [1] (p. 6).

For specific parts of Asia, it is predicted that crop yield will decline up to $10 \%$ in the 2020s and 30\% in the 2050s compared to the 1990s [2] (p. 849). Vietnam, in Southeast Asia, is expected to be one of the most badly affected countries by climate change, due to its extensive coastline, its agriculture-oriented economy, and its underdeveloped rural areas [3-5]. The coastline is especially vulnerable because of population pressures and predicted sea level rise [6]. Furthermore, it has been reported that the average temperature in the region will increase by 0.8 to 2.7 degrees Celsius by 2060 [7] and that sea levels will rise by $78 \mathrm{~cm}$ to $95 \mathrm{~cm}$ by 2100 (simulated under a high emission scenario A1F1 which assumes a continued fossil-intensive energy production) [8]. It has also been reported that climate change (CC) related to disasters, such as typhoons, floods, and droughts, will be harmful to rice cultivation due to significant alterations in the soil composition and in the availability of freshwater [5]. Researchers have indicated that the central coastal region of Vietnam is highly vulnerable to CC [3,9-11], with a predicted average sea level rise of 
about $22 \mathrm{~cm}$ by 2050 and $73 \mathrm{~cm}$ by 2100 [12]. The impact of the expected sea level rise is greatest in coastal provinces of Central Vietnam, driving problems such as saltwater intrusion [8] (p.10).

Due to the impact of $C C$, it is predicted that rice production in Vietnam will suffer a 3.4-6.7 percent reduction in productivity by 2050, compared to the 1990s [13]. In Central Vietnam, rice yield will reduce by $13.9 \%$ to $23.5 \%$ during winter as temperatures increase by $0.35-1.72{ }^{\circ} \mathrm{C}$ and by $0.93-3.69{ }^{\circ} \mathrm{C}$, respectively [10]. These losses, in turn, will have a substantial impact not only on the livelihoods of local farmers, but also on the stability of the economy as a whole. Given these impacts, rice production will become "problematic" if suitable adaptation and mitigation strategies are not implemented in time $[14,15]$. Therefore, identifying suitable adaptation measures is an urgent agricultural policy action in the central coastal region of Vietnam. CC adaptation measures serve multiple goals, including reducing risks and vulnerabilities, and enhancing the adaptive capacity of society as a whole [16]. At the same time, selecting suitable adaptation options is often influenced by factors other than CC-related variables [3], such as the policy framework and market conditions [17]. Selecting the best adaptation should thus look beyond climate risks to consider other goals, such as social and economic benefits. The decision-making process surrounding the ranking of different adaptation options requires the mobilization of knowledge and the experience of researchers and local authorities, as well as the farmers involved.

Given the diversity of goals to be considered in identifying suitable CC adaptation methods, many authors consider multicriteria assessment (MCA) to be the most suitable tool [18-20]. Among the different MCA approaches, we focused on the analytic hierarchy process (AHP) method for four reasons: (1) it is appropriate for combining multiple stakeholders in group decision making [21] (pp. 9-26); (2) it is simple and easy to understand by applying ratio scales [22]; (3) it is useful in combining both subjective information (reports, preferences) and objective information (expert knowledge) [23]; (4) it is a special method using a hierarchy tree to define a problem in terms of a goal, criteria, and alternatives [24]. However, to the best of our knowledge, little research has been devoted to ranking CC adaptation options using the AHP method (see Supplementary Materials A for an overview of AHP applications on CC adaptation). In Vietnam, only a study by Sen (2016) [25] applied AHP to investigate adaptation to increased risks of flooding, drought, and saltwater intrusion in the coastal region of the Phu Vang district, Thua Thien Hue province, Vietnam. Sen (2016) classified the alternative adaptation options into three groups: agriculture, husbandry, and aquaculture. Agriculture was ranked highest amongst these groups, while aquaculture was ranked lowest. Within the group of agricultural adaptation options, planting bitter melon during the wrong season was given top priority. In the aquaculture group, poly-culture of mullets gained the highest scores. The study by Sen (2016) explored adaptation strategies to improve the livelihoods of local farmers, but did not exclusively focus on adaptation to saltwater intrusion (SWI) for rice production.

In an effort to complement the work of Sen (2016), the main objective of this paper was to apply the AHP method to rank the potential SWI adaptation options for rice farmers in the central coastal area of Vietnam, taking into account sustainability criteria. In doing so, we drew on input from all stakeholders involved in climate change adaptation decisions at the local level: people committees, department of agriculture and rural development, department of economy and sociology, department of planning and investment, agricultural extension center, farmers' union, women's union, division of plant protection, cooperatives, agricultural firms, and individual farmers. On the practical level, the aim of our research was to support local authorities in these study areas in their efforts to develop strategies for the local agricultural sector, in which CC impacts (and SWI) are taken into account. Every five years, local authorities decide on which SWI adaptation methods to promote in the region, taking into account different criteria related to social and economic development, food security, and land allocation. AHP is well suited to bring together these different criteria and potential differences in appreciation of the adaptation methods of different stakeholders. On a more general level, the research presented in this paper demonstrates 
that MCA provides suitable tools to study complex sustainability issues-in this case at the crossroads of regional resilience (coastal areas in developing countries) and sectorial resilience (agriculture and rice cultivation in particular). Many of the lessons learned are valuable to the wider literature on CC adaptation, ranging from the data collection process, over the identification of criteria, to the development of indicators in the AHP application.

The remainder of paper is structured as follows: Section 2 focuses on "Material and Methods" and describes the methodology, the study areas, the data collection process, and the AHP decision support model. The results of our analysis are presented in Section 3 ("Results and Discussion"), while Section 4 ("Conclusions") looks into the policy implications of our research.

\section{Materials and Methods}

\subsection{Methodology}

MCA provides decision makers with a systematic way to make sense of the wide array of relevant information and enables them to create a structured framework for comparing a set of identified options across a range of criteria [20]. As a result, MCA is a highly relevant tool for making CC adaptation choices, given that the criteria used in MCA can include uncertainty and other intangible elements of CC adaptation [26]. Therefore, it is no surprise that the technique has been applied as a decision support tool in CC adaptation studies $[16,18,19,26-28]$.

MCA approaches include multiattribute utility theory (MAUT), analytical hierarchy process (AHP), and outranking methods. In this paper, we focused on AHP-a method developed by Thomas L. Saaty in the 1970s that is now widely applied in many fields, including strategic planning, resource allocation, marketing, education, healthcare, and public policy [29-35]. Saaty T.L. (2016) defined AHP as a "relative measurement on absolute scales of both tangible and intangible indicators that is based on the judgment of knowledgeable and expert people and on existing measurement and statistics needed to make a decision" [21]. Thanks to its advantages in comprising numerous qualitative and quantitative factors [36], its flexibility of application [16], its potential to differentiate the importance of each indicator [37], and control over internal consistency [38], AHP can overcome some of the shortcomings of other techniques-e.g., an exclusive focus on expert preferences or the use of monetary valuation techniques. AHP identifies the best option from a set of alternatives by applying a hierarchical foundation (set of indicators and subindicators), and, in doing so, it allows for nonquantitative higher-level indicators [39]. Finally, decisions are based on combining multidimensional scales of measurement into a single, so called "one-dimensional", scale of priorities [21]. The main limitations of AHP include the process requiring exact calculations and the potentially large influence of stakeholders' opinions on the final outcome [40]. The latter can, however, be further investigated using sensitivity analyses on the weights given by experts.

\subsection{Study Areas}

The central coastal region of Vietnam is dominated by a subtropical humid climate with two main seasons: dry and rainy. In our study, we selected the Thua Thien Hue and Quang Nam Province as representative for the northern and southern parts, respectively. These two provinces are leaders in both rice production surface and proportion of SWIaffected areas. In the Thua Thien Hue province, $6 \%$ of the 54,400 ha paddy land is affected by SWI. Within this province, the district of Quang Dien was selected as the first study area, given its high proportion of paddy fields affected by SWI (13\%). The province of Quang Nam has 87,396 ha of paddy land, of which 7816 ha is saline (11\%) [41] Here, we chose the Duy Xuyen district as the second study area, since it is the district in which SWI is most problematic - affecting 2258 hectares of paddy fields, or $29.1 \%$ of the total paddy land surface [42]. In each district, three different communes were selected as representatives of three different levels of SWI impacts (high, moderate, and mild). In both study areas, the majority of affected paddy fields are located alongside the coast or a river influenced 
by the tidal regime. The risk of SWI is particularly high in the summer season, with large negative impacts on rice production.

\subsection{Data Collection Process}

In this study, we drew on field observations, a literature review, face-to-face interviews, and focus group discussions (FGDs) to collect the data for the AHP analysis. We conducted a literature review of related studies and an analysis of secondary data related to SWI issues in both study areas, as well as on their demographic, natural, and economic characteristics. Moreover, based on literature review, a number of potential components that can be used to assess an adaption method were listed. Field observations were used to obtain an overview of the adaption methods that are currently being applied. The stakeholders that participated in the key informant interviews and FGDs were the representatives of organizations that involve in drawing, making, and implementing the policies related to CC adaption (Supplementary Materials B). Face-to-face interviews were carried out with stakeholders and experts ( 8 in total, Supplementary Materials $\mathrm{C} 1$ ) from different organizations to collect data related to the policy framework in place to promote effective SWI adaption options in the study areas. A first FGD was conducted, in which representatives of the local authorities and researchers working on climate change participated. The purpose of this first FGD was to assess the current situation of rice production and the impacts of SWI in the both provinces and to verify and select the most applicable components and indicators for evaluating SWI adaption practices. Afterwards, two additional FGDs were conducted in each district—one with local staff to develop pairwise comparison matrices, and one with local cooperatives and farmers to rate the different adaptation methods on the different subindicators. The knowledge and expertise of local farmers was vital to the assessment, as the decision on whether or not to implement adaptation methods is ultimately in their hands. Figure 1 presents the full data collection process, while a detailed description of each research step (methods and outcomes) is presented in Section 2.3. The entire data collection process included six steps to (a) collect inputs (the bold arrows) and (b) provide outputs (bold and dotted arrows). More detailed information on the FGDs is presented is Supplementary Materials C2.

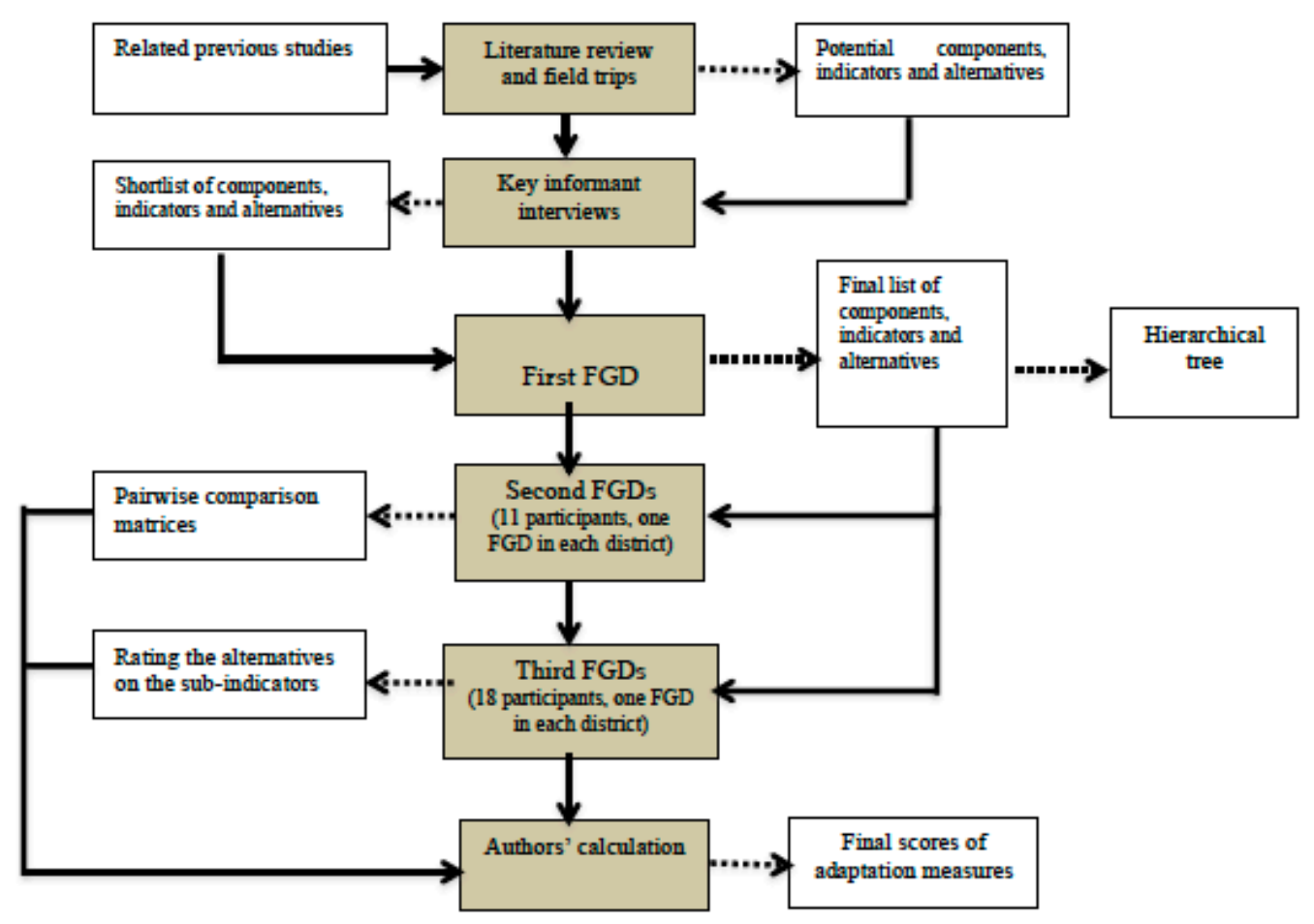

Figure 1. Data collection process. (Source: authors' synthesis, 2020). 


\subsection{AHP Decision Support Model}

\subsubsection{Development of Components, Indicators, and Alternatives}

We started with an extensive literature review to develop the first list of potential components. A number of authors have developed a series of components for use in identifying "successful" adaptation options. Stern (2008) and Weiland et al. (2015) used a list of three components: efficiency, effectiveness, and equity [43,44], while Yohe and Tol (2002) focused instead on efficiency, feasibility, and acceptability [45]. Others have considered that components related to development issues should be applied when reviewing different adaptation options, including feasibility, efficacy/effectiveness, efficiency, acceptability/legitimacy, equity, and sustainability [46-48]. Aside from the components mentioned above, Dixit and McGray (2013) added several components, such as urgency, robustness, and practicality [20]. Finally, Brooks et al. (2011) framed adaptation options in terms of technical and institutional sustainability [47]. Sen (2016) has developed four main criteria: coherence, effectiveness, resistance, and sustainability [25]. Each of these components comprises different indicators that cover three dimensions-society, economy and ecology - and the weights for the different indicators were set through focus group discussions. Drawing on this literature review, we identified a first list of 8 potential components, including effectiveness, sustainability, efficiency, equity, feasibility, ability to confront and adapt, robustness, and practically. This list was carefully revised by experts in order to reduce the number of components and ensure suitability for the purposes of our study. The shortlist included four components: coherence, efficiency, ability to confront and adapt, and sustainability and equity.

Next, we identified indicators for each of the components for use in the next step of our analysis. Indicators for decision-making and selection of adaptation alternatives should be simple, measurable, analytically sound, relevant to policy, and transparent [48]. In particular, the indicators in our paper needed to be applicable to the different SWI adaptation measures under consideration and be appropriate within the context of both study areas. The potential indicators (Supplementary Materials D) were shortened and grouped respectively into 4 components (Supplementary Materials E) that were decided by key informants.

Regarding the alternative adaptation options to be included in our study, we largely drew on the Vietnamese Government's policy related to CC adaptation. Drawing on field observations and a literature review, potential alternatives were reduced to 11 (Supplementary Materials F) before submitting them to participants in the first FGD. Here, the alternatives were analyzed using two conditions: (1) Is the alternative compatible with the "soft solutions" in the Second Action Plan of Ministry of Agriculture and Rural Development (Supplementary Materials G)? (2) Is it compatible with the natural, social, and economic conditions of the study area under consideration?

The first output of the first FGD was a final list of 4 components and 10 indicators, as well as 35 subindicators (Table 1). The descriptions of components and indicators are introduced in Supplementary Materials H. 
Table 1. Components and indicators.

\begin{tabular}{|c|c|c|}
\hline Component & Indicator & Subindicator \\
\hline \multirow{3}{*}{$\begin{array}{l}\text { Coherence } \\
\text { (A1) }\end{array}$} & $\begin{array}{l}\text { (B1) Coherent with the natural conditions } \\
(1=\text { absolutely not coherent, } 5=\text { very } \\
\text { coherent })\end{array}$ & $\begin{array}{l}\text { (C1) Coherent with soil conditions } \\
\text { (C2) Coherent with climate conditions } \\
\text { (C3) Coherent with local ecosystems }\end{array}$ \\
\hline & $\begin{array}{l}\text { (B2) Coherent with community capacity } \\
(1=\text { absolutely not coherent, } 5 \text { = very } \\
\text { coherent })\end{array}$ & $\begin{array}{l}\text { (C4) Coherent with the skills and knowledge of farmers } \\
\text { (C5) Coherent with local experiences and local backgrounds } \\
\text { (not too new) } \\
\text { (C6) Coherent with the financial and investment capacity of } \\
\text { farmers }\end{array}$ \\
\hline & $\begin{array}{l}\text { (B3) Coherent with local customs and } \\
\text { policies } \\
(1=\text { absolutely not coherent, } 5=\text { very } \\
\text { coherent })\end{array}$ & $\begin{array}{l}\text { (C7) Coherent with local policies } \\
\text { (C8) Coherent with community needs } \\
\text { (C9) Coherent with local customs }\end{array}$ \\
\hline \multirow{3}{*}{$\begin{array}{l}\text { Efficiency } \\
\text { (A2) }\end{array}$} & (B4) Economic efficiency & $\begin{array}{l}\text { (C10) Yield }(1=\text { very low, } 5=\text { very high }) \\
(\text { C11 }) \text { Cost of production }(1=\text { very high, } 5=\text { very low }) \\
\text { (C12) Profits }(1=\text { very low, } 5=\text { very high }) \\
\text { (C13) Risks }(1=\text { very high, } 5=\text { very low }) \\
\text { (C14) Stability of input prices }(1=\text { absolutely not stable, } 5=\text { very } \\
\text { stable) } \\
\text { (C15) Stability of output market }(1=\text { absolutely not stable, } 5= \\
\text { very stable) }\end{array}$ \\
\hline & (B5) Social efficiency & $\begin{array}{l}\text { (C16) Improving the living standards of vulnerable groups } \\
\text { (women, children, poor people) }(1=\text { not improved, } 5=\text { very } \\
\text { improved) } \\
\text { (C17) Risks of increasing the gap between rich and poor people } \\
\text { (1= very high, } 5=\text { very low) } \\
\text { (C18) Job opportunities ( } 1=\text { very low, } 5=\text { very high) }\end{array}$ \\
\hline & (B6) Environmental efficiency & $\begin{array}{l}(\mathrm{C} 19) \text { Risk of soil erosion and land degradation }(1=\text { high risk, } 5 \\
=\text { low risk }) \\
(\mathrm{C} 20) \text { Risk of water pollution }(1=\text { high risk, } 5=\text { low risk }) \\
(\mathrm{C} 21) \text { Risk of exhausting water sources }(1=\text { high risk, } 5=\text { low } \\
\text { risk }) \\
(\mathrm{C} 22) \text { Risk of air pollution }(1=\text { high risk, } 5=\text { low risk })\end{array}$ \\
\hline \multirow{2}{*}{$\begin{array}{l}\text { Ability to Confront } \\
\text { and Adapt } \\
\text { (A3) }\end{array}$} & (B7) Ability to confront & $\begin{array}{l}\text { (C23) Ability to confront floods }(1=\text { very low, } 5=\text { very high }) \\
\text { (C24) Ability to confront droughts }(1=\text { very low, } 5=\text { very high) } \\
\text { (C25) Ability to confront saltwater intrusion }(1=\text { very low, } 5= \\
\text { very high) }\end{array}$ \\
\hline & (B8) Ability to adapt & $\begin{array}{l}\text { (C26) Ability to recover after saltwater intrusion }(1=\text { very low, } 5 \\
=\text { very high) } \\
\text { (C27) Crop season flexibility to avoid SWI }(1=\text { very inflexible, } 5 \\
=\text { very flexible) } \\
\text { (C28) Ability to confront a worsening SWI situation }(1=\text { minor } \\
\text { limitation, } 5=\text { major limitation) }\end{array}$ \\
\hline \multirow{2}{*}{$\begin{array}{l}\text { Sustainability and } \\
\text { Equity } \\
\text { (A4) }\end{array}$} & (B9) Sustainability & $\begin{array}{l}\text { (C29) Income diversity }(1=\text { low diversified, } 5=\text { high diversified }) \\
\text { (C30) Coherence with CC scenarios }(1=\text { very incoherent, } 5= \\
\text { very coherent) } \\
\text { (C31) Expanding abilities (adaptation options can be upscaled }) \\
(1=\text { very low, } 5=\text { very high) } \\
\text { (C32) Developing abilities (adaptation options can be } \\
\text { maintained for long time) }(1=\text { very low, } 5=\text { very high })\end{array}$ \\
\hline & (B10) Equity & $\begin{array}{l}\text { (C33) Proportion of farmers impacted by SWI who can access } \\
\text { information about adaptation options ( } 1=\text { very small } \\
\text { proportion, } 5=\text { very large proportion) } \\
\text { (C34) Proportion of farmers impacted by SWI who can apply } \\
\text { adaptation options ( } 1=\text { very small proportion, } 5=\text { very large } \\
\text { proportion) } \\
\text { (C35) Vulnerable groups (women, poor people, elderly) are } \\
\text { targeted specifically through the adaptation options }(1=\text { low } \\
\text { disagreement, } 5=\text { high agreement) }\end{array}$ \\
\hline
\end{tabular}


The second output of the first FGD was the final list of alternatives. The alternatives needed to be applicable to address SWI problems in agriculture and include both adaptation methods that are currently being applied, as well as other potentially valuable methods for application in the near future (Table 2).

Table 2. Current and potential adaptation methods in both study areas.

\begin{tabular}{|c|c|c|c|}
\hline & & Duy Xuyen & Quang Dien \\
\hline \multirow[b]{3}{*}{ Current alternative } & Alternative 1 & \multicolumn{2}{|c|}{$\begin{array}{c}\text { Apply new varieties of paddy rice: farmers change to new varieties that are } \\
\text { more salt-tolerant knowing that the yield might be lower. }\end{array}$} \\
\hline & Alternative 2 & \multicolumn{2}{|c|}{$\begin{array}{c}\text { Switch to shrimp production: farmers convert their land into shrimp ponds } \\
\text { and accept higher risks. }\end{array}$} \\
\hline & Alternatives $3 \& 4$ & $\begin{array}{l}\text { Plant papyrus: farmers convert their } \\
\text { paddy fields into papyrus fields. Papyrus } \\
\text { cultivation does not require a lot of } \\
\text { maintenance time and the cost of inputs } \\
\text { is lower for papyrus than for } \\
\text { rice production. }\end{array}$ & $\begin{array}{l}\text { Apply lotus-fish model: } \\
\text { farmers convert paddy fields } \\
\text { into fishponds where lotus } \\
\text { flowers will also be cultivated }\end{array}$ \\
\hline $\begin{array}{l}\text { Potential } \\
\text { alternative }\end{array}$ & Alternative 5 & $\begin{array}{l}\text { Apply coconut-fish model: this method } \\
\text { involves converting land into canals } \\
\text { where fish will be kept, while planting } \\
\text { coconut trees alongside the banks. }\end{array}$ & $\begin{array}{l}\text { No potential alternative was } \\
\text { reported for this district. }\end{array}$ \\
\hline
\end{tabular}

(Source: authors' analysis, 2020).

There are two reasons why no potential alternative was reported for the Quang Dien district. First, the lotus-fish model was only very recently operationalized (small scale) and was still considered to be a mostly potential alternative by many experts in the FGD. Second, SWI-related problems in this study area are more serious than in the Duy Xuyen district due to the fact that Quang Dien mostly suffers from saline groundwater. As a result, it is more difficult to find a suitable adaptation option for Quang Dien district for application in the (near) future.

In addition, the output from the first FGD helped us to draw a hierarchical tree (Supplementary Materials I) around the main goal (problem) setting out the components, indicators, and subindicators by which the different alternatives will be assessed. The hierarchical tree is a nontraditional decision tree for a number of reasons, including the fact that each level of the tree may represent a different layer of the problem (e.g., social, political, economic) and these levels can be evaluated against each other [24]. In general, the higher levels of the tree will represent more general characteristics of the problem, while the more specific ones are introduced in the lower levels.

\subsubsection{Scoring Alternatives}

Results of AHP were gained by conducting pairwise comparison, weighting coefficients for the matrix, calculating consistency rate and ranking alternatives. The AHP technique "derives relative scales of absolute numbers known as priorities from judgments expressed numerically on absolute fundamental scales" [49] (p. 365). The scales that were used to pairwise compare the importance of components and indicators (subindicators) applied ratings between 1 (equal importance) and 9 (one is of extreme greater importance than the other), as illustrated in Table 3. One of the advantages of this technique is that it allows independent focus on the relationship between two of the components or indicators, while not considering the others [24]. 
Table 3. Fundamental scale of absolute numbers.

\begin{tabular}{cc}
\hline Intensity of Importance & Definition \\
\hline 1 & Equal importance both elements \\
3 & Weak importance of one element over another \\
5 & Strong importance of one element over another \\
7 & Very strong or demonstrated importance of one element \\
9 & over another \\
$2,4,6,8$ & Extreme importance of one element over another \\
Intermediate values between two adjacent judgments
\end{tabular}

We illustrate the weighting procedure for indicators in the hierarchical tree, which comprises three indicators, below. Table 4 shows how pairwise comparison works by building a pairwise comparison matrix of these indicators. The same procedure was repeated for all components and subindicators.

Table 4. Pairwise comparison matrix of three indicators.

\begin{tabular}{cccccc}
\hline Indicator & Indicator 1 & Indicator 2 & Indicator 3 & Eigenvector & Weight \\
\hline Indicator 1 & $W_{11}$ & $W_{12}$ & $W_{13}$ & $|W 1|$ & $\beta_{1}$ \\
Indicator 2 & $\frac{1}{W_{12}}$ & $W_{22}$ & $W_{23}$ & $|W 2|$ & $\beta_{2}$ \\
Indicator 3 & $\frac{1}{W_{13}}$ & $\frac{1}{W_{23}}$ & $W_{33}$ & $|W 3|$ & $\beta_{3}$ \\
Total & $\sum W_{123}^{1}$ & $\sum W_{123}^{2}$ & $\sum W_{123}^{3}$ & & 1 \\
\hline
\end{tabular}

(Source: Sen (2016)).

In the above table:

$$
\begin{gathered}
\sum W_{123}^{1}=W_{11}+\frac{1}{W_{12}}+\frac{1}{W_{13}} \\
|W 1|=W_{11} / W_{123}^{1}+W_{12} / W_{123}^{2}+W_{13} / W_{123}^{3} \\
|W 2|=W_{123}^{1} / W_{12}+W_{22} / W_{123}^{2}+W_{23} / W_{123}^{3} \\
|W 3|=W_{123}^{1} / W_{13}+W_{123}^{2} / W_{23}+W_{33} / W_{123}^{3} \\
\beta_{1}=\frac{1}{3}|W 1| \quad \beta_{2}=\frac{1}{3}|W 2| \quad \beta_{3}=\frac{1}{3}|W 3| .
\end{gathered}
$$

In order to derive pairwise comparison matrices, a second FGD was conducted in each study area individually. In these FDGs, the entire group of participants was considered as one individual who rated the intensity of the importance of the different components, indicators, and subindicators in a pairwise comparison. We thus considered consensus data from the FGDs to calculate the respective weights for all levels of the components. The consistency of judgments was checked to ensure the proportionality and transitivity of the results by calculating the consistency ratio $(\mathrm{CR})$ :

$$
\mathrm{CR}=\frac{C I}{R I}
$$

where: CI: consistency index and RI: random index.

With:

$$
\mathrm{CI}=\frac{\lambda_{\max }-n}{n-1}
$$

where: $\lambda_{\max }$ : the eigenvalue of the matrix and $\mathrm{n}$ : the size of the matrix.

A consistency ratio of up to $10 \%$ is tolerable, yet slight deviations do not pose a problem. Large deviations, however, imply that the judgments are not optimal and have to be improved [24].

Table 5 illustrates how to come to a ranking for the different adaptation options, we first calculated the priorities of subindicators using the weights determined in step 
2. Let $\gamma_{i j}$ be the weight for subindicator $i j$, so that the priorities can be calculated by the following formula:

$$
\text { Priorities }\left(\delta_{i j}\right)=\beta_{i} \times \gamma_{i j}
$$

Table 5. Weight of each subindicator.

\begin{tabular}{clc}
\hline Indicator & Subindicator & Priorities \\
\hline \multirow{3}{*}{ Indicator $1\left(\beta_{1}\right)$} & Subindicator 11 $\left(\gamma_{11}\right)$ & $\delta_{11}$ \\
& Subindicator 12 $\left(\gamma_{12}\right)$ & $\delta_{12}$ \\
& Subindicator 13 $\left(\gamma_{13}\right)$ & $\delta_{13}$ \\
\hline \multirow{3}{*}{ Indicator 2 $\left(\beta_{2}\right)$} & Subindicator 21 $\left(\gamma_{21}\right)$ & $\delta_{21}$ \\
& Subindicator 22 $\left(\gamma_{22}\right)$ & $\delta_{22}$ \\
& Subindicator 23 $\left(\gamma_{23}\right)$ & $\delta_{23}$ \\
\hline \multirow{2}{*}{ Indicator 3 $\left(\beta_{3}\right)$} & Subindicator 31 $\left(\gamma_{31}\right)$ & $\delta_{31}$ \\
& Subindicator 32 $\left(\gamma_{32}\right)$ & $\delta_{32}$ \\
& Subindicator 33 $\left(\gamma_{33}\right)$ & $\delta_{33}$ \\
\hline
\end{tabular}

(Source: adapted from Le Thi Hoa Sen (2016).

Second, we derived the score for each adaptation option $n$ of each subindicator through the following formula:

$$
P_{i j}=a_{i j} * \delta_{i j}
$$

where: $P_{i j}$ : score of adaption option $n$ for the subindicator $\mathrm{ij}$;

$a_{i j}$ : rating point of subindicator $i j$ of alternative n (Likert scale);

$\delta_{i j}$ : priorities of subindicator $i j$.

$$
P_{n}=\sum_{i, j} P_{i j}
$$

where: $P_{n}$ : final score of adaption option $n$.

To derive the final score for each adaption option, we summed up the multiplication between the priorities of each subindicator and the ratings given to each subindicator for each alternative. Ranking the alternatives is based on the final scores, with the highest final score indicating the best one.

In our study, we combined two ways of weighting to obtain the final score for each alternative, including prioritizing by pairwise comparison and rating the alternatives on the subindicators. Hence, we asked the participants of the third FGDs to agree or disagree (on a 1-5 Likert scale) on a number of statements related to the different subindicators with respect to each alternative. The main reason for choosing not to apply a pairwise comparison for all alternatives with respect to the different subindicators was that such a procedure proved difficult to explain to local farmers-the main participants in the FGDs. Rating the different subindicators individually was found to be more feasible and worked better for most of the participants in our FGDs. In addition, Sen (2016) reported that such a procedure may actually result in more accurate rankings compared to working with pairwise comparisons [25].

After finalizing the ranking for the different alternatives considered in both study areas, a number of sensitivity analyses were performed to identify to what extent changes in the weights of the different components could affect the final ranking.

\section{Results and Discussion}

\subsection{Deriving Priorities (Weights) for the Different Components and Indicators}

Tables 6 and 7 show the priorities of four components with respect to the goal in both study areas. We found that sustainability and equity obtained the highest score in both districts, while coherence ranked the lowest. The final weights for both components were in the same order of magnitude (0.529 and 0.454 , and 0.045 and 0.061 , respectively). In the district of Duy Xuyen, efficiency was found to be the second most important component 
(0.241), followed by ability to confront and adapt (0.185), whereas in the district of Quang Dien, the order was reversed. Here, ability to confront and adapt ranked second (0.383), followed by efficiency (0.102).

Table 6. Pairwise comparison matrix of components (Duy Xuyen District).

\begin{tabular}{cccccc}
\hline Indicator & Coherence & Efficiency & $\begin{array}{c}\text { Ability to Confront } \\
\text { and Adapt }\end{array}$ & $\begin{array}{c}\text { Sustainability } \\
\text { and Equity }\end{array}$ & Priorities \\
\hline $\begin{array}{c}\text { Coherence } \\
\text { Efficiency }\end{array}$ & 1 & $1 / 5$ & $1 / 6$ & $1 / 9$ & 0.045 \\
$\begin{array}{c}\text { Ability to } \\
\begin{array}{c}\text { onfront and } \\
\text { Adapt }\end{array}\end{array}$ & 6 & 1 & 2 & $1 / 3$ & 0.241 \\
$\begin{array}{c}\text { Sustainability } \\
\text { and Equity }\end{array}$ & 9 & $1 / 2$ & 1 & $1 / 3$ & 0.185 \\
\hline & 3 & 3 & 1 & 0.529 \\
(Source: authors' analysis, 2020). & & $\lambda_{\text {max }}=4.127$ & $\mathrm{CI}=0.042$ & $\mathrm{CR}=0.047$ \\
\hline
\end{tabular}

(Source: authors' analysis, 2020).

Table 7. Pairwise comparison matrix of the components (Quang Dien District).

\begin{tabular}{cccccc}
\hline Indicator & Coherence & Efficiency & $\begin{array}{c}\text { Ability to Confront } \\
\text { and Adapt }\end{array}$ & $\begin{array}{c}\text { Sustainability } \\
\text { and Equity }\end{array}$ & Priorities \\
\hline $\begin{array}{c}\text { Coherence } \\
\text { Efficiency }\end{array}$ & 1 & $1 / 2$ & $1 / 5$ & $1 / 8$ & 0.061 \\
$\begin{array}{c}\text { Ability to } \\
\begin{array}{c}\text { Confront and } \\
\text { Adapt }\end{array}\end{array}$ & 5 & 1 & $1 / 4$ & $1 / 5$ & 0.102 \\
$\begin{array}{c}\text { Sustainability } \\
\text { and Equity }\end{array}$ & 8 & 5 & 1 & 1 & 0.383 \\
\hline
\end{tabular}

(Source: authors' analysis, 2020).

From the FGDs, we were able to identify a number of explanations for these findings. First, CC impacts are increasingly better understood at the local level in Vietnam, and there is a growing awareness concerning the persistence of the problem. As a result, the ideal adaptation method is one that can be applied in the long term-explaining the high weight for sustainability and equity. Likewise, participants argued that problems of shortterm incoherence relating to the different adaptation methods under scrutiny should not be given a high weight, as this incoherence can be overcome by reallocating resources over time-e.g., investing in new technology, such as SWI warning systems; overcoming capital requirements for some of the adaptation methods by exploring more labor-intensive variants; delivering training courses in case farmers lack knowledge and information on adaptation options; or adjusting crop seasons if weather conditions change marginally. The substantial difference in the weight of ability to confront and adapt between both districts ( 0.185 for Duy Xuyen vs. 0.383 for Quang Dien) can be related to the differences in persistence of SWI-related problems. In the latter district, SWI problems are more severe as the groundwater is saline, whereas in the former district, SWI impacts originate from saline freshwater, which is easier to control through well-constructed pumping systems. Noticeably, despite the fact that separate FGDs were organized in both study areas, the rankings of the components were rather similar. This implies that the stakeholders in the different areas envision similar CC adaptation strategies in spite of geographical and cultural differences between both districts. The weights and priorities for all indicators and subindicators are reported in Supplementary Materials J. We found that all CR values were less than 0.10 (in this paper, we used Random Index's value of Wharton), satisfying the condition set in AHP analysis. We could thus make use of the FGD participants' judgments and proceed to the next steps in AHP.

After setting the priorities for all components, indicators, and subindicators through pairwise comparisons, each adaptation method was rated on a 1 to 5 scale with re- 
spect to all subindicators. The pairwise comparison and the scores for each alternative on the different levels are presented from Tables S6-S19 in Supplementary Materials J. Table 8 presents the final scores for the different alternatives under consideration in the two study areas.

Table 8. Final scores for alternatives in both study areas.

\begin{tabular}{ccc}
\hline & Duy Xuyen District & Quang Dien District \\
\hline Coconut-fish model & 4.21 & 3.69 \\
Lotus-fish model & & 3.32 \\
Shrimp production & 3.75 & 2.78 \\
New rice varieties & 3.68 & \\
Papyrus cultivation & 2.97 & \\
\hline
\end{tabular}

(Source: data analysis, 2020).

Looking at the different adaptation options solicited in the FDGs for the Duy Xuyen district, the highest priority was given to the coconut-fish model (4.21), followed by shrimp production (3.75), new rice varieties (3.68), and papyrus cultivation (2.97). The results in Table S19 in Supplementary Materials J. indicate that among the four adaptation methods that were investigated, the coconut-fish model contains the highest efficiency, ensures equity, and is a suitable method to confront and adapt to the current SWI situation in this study area. In the district of Quang Dien, the lotus-fish model was the most preferred alternative (3.69), mostly because of its recent successful implementation. Next in the ranking, we found new rice varieties (3.32) and shrimp production (2.78). The ranking order in Table 8 partly reflects the geographical, social, and economic characteristics of each district. Shrimp production was preferred more in Duy Xuyen than in Quang Dien because this adaptation method can make use of the well-constructed pumping system in the former district, reducing the risks involved.

\subsection{Sensitivity Analysis}

The final ranking of alternatives in an AHP might strongly depend on the weights given to each component in the hierarchical tree. Therefore, it is necessary to perform sensitivity analyses and explore to what extent the final scores and rankings of the alternatives change with changes in the weights. This is an important step in AHP that allows investigation of the robustness of the outcome and identifies its main drivers [50].

Figures 2 and 3 illustrate to what extent the final ranking of the adaptation methods would change if we changed the weights of the four components. We found that using equal weights would result in a change in the ranking of alternatives in Duy Xuyen district: papyrus cultivation would become the second most preferred option instead of being ranked last using the FGD weights. This is because papyrus cultivation received high scores on the first and third component (coherence and ability to confront and adapt)components that were identified as less important in the FGDs. Using equal weights increased the weights of both components from $4.5 \%$ to $25 \%$, and from $18.5 \%$ to $25 \%$, respectively, improving the ranking of papyrus cultivation. Using equal weights for the Quang Dien district did not alter the ranking of alternatives. However, the final scores for new varieties of rice and the lotus-fish model slightly decreased because of the weight reduction in the ability to confront and adapt component (from 38\% to 25\%), on which both alternatives scored better than shrimp production. In the sensitivity analysis, we also made use of a second alternative weight set that gave a weight of $50 \%$ to sustainability and equity and divided the remaining 50\% over the other three components. Using this alternative weight set, we found that the coconut-fish model was still the most preferred adaptation method in Duy Xuyen, yet new rice varieties now beat shrimp production for second place. In the district of Quang Dien, the ranking of alternatives remained the same for the second alternative weight set, but we observed minor changes in the final scores. In conclusion, the AHP results were more sensitive in the Duy Xuyen district than in the Quang Dien district. However, the rankings of alternative adaptation methods in both 
districts were relatively robust, since the order only changed when the weights for each component changed by more than $10 \%$.

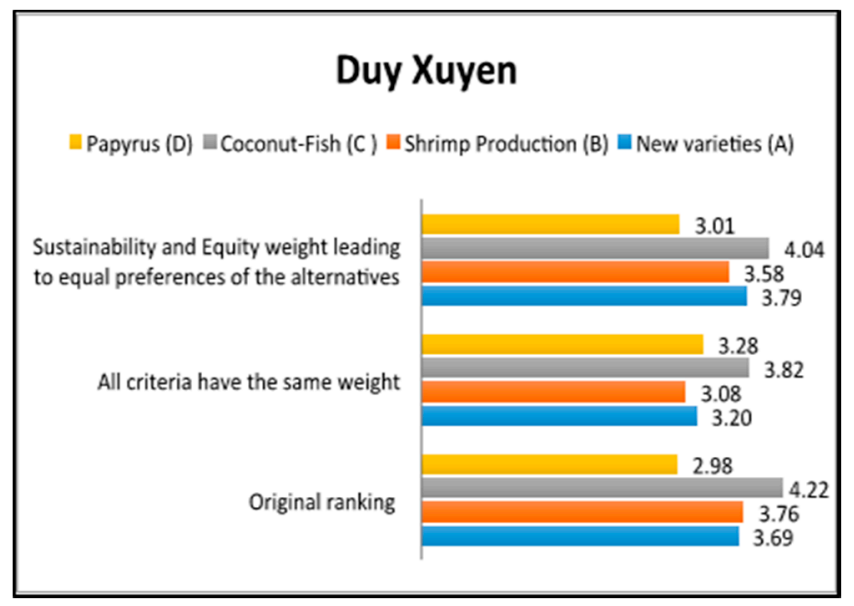

Figure 2. Sensitivity analysis in Duy Xuyen district. (Source: authors' calculation, 2020).

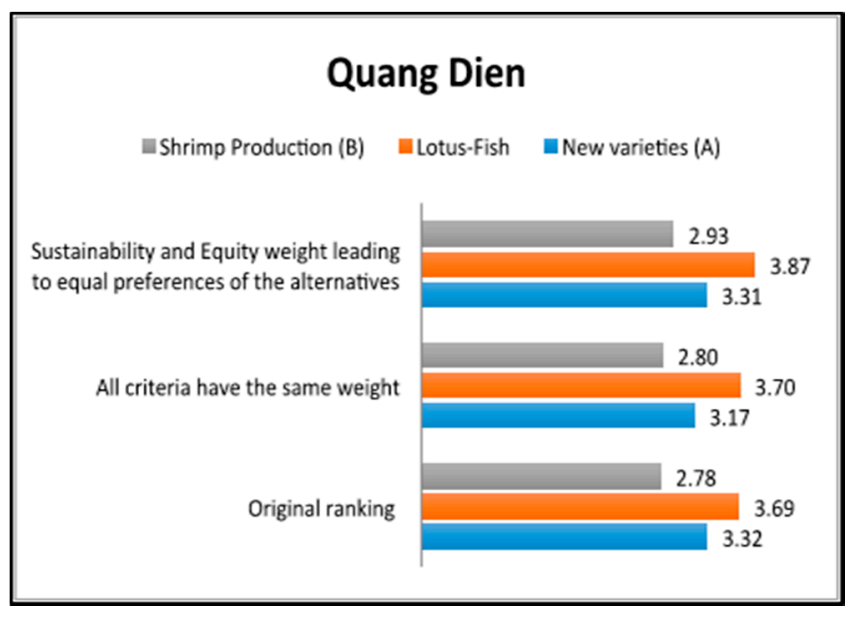

Figure 3. Sensitivity analysis in Quang Dien district. (Source: authors' calculation, 2020).

\section{Conclusions}

Given the multidimensional nature of climate change issues, the knowledge and experience of different stakeholders, including researchers, local authorities, and local farmers, need to be mobilized when addressing issues relating to saltwater intrusion. The multidimensionality also turns decision-making related to CC adaptation into a complex process that has to consider a wide range of criteria when investigating a range of alternative adaptation methods. Through FGDs in both study areas we found that sustainability and equity is the most important component to be considered, while coherence is least important. These results indicate that stakeholders focus more on long-term strategies when tackling CC issues. Among the different adaptation methods in this study, the coconut-fish model was the most preferred adaptation method in the Duy Xuyen district, whereas the lotus-fish model ranked first in the Quang Dien district. These priorities again reflect a preference for long-term SWI adaptation solutions in both study areas. The FGDs revealed a number of reasons to explain why the coconut-fish Model ranked first in Duy Xuyen. First, this relatively recent method has been successfully applied in other areas in Vietnam, mostly in the Mekong Delta region. Second, this model is part of the long-term strategic plan for SWI adaptation in the Quang Nam province. Finally, the coconut-fish model can increase farmers' income through revenues from ecological tourism (fishing and camping 
under coconuts), which is booming in Vietnam. We also found three reasons that explain why the lotus-fish model ranked highest in the Quang Dien district. The first reason is that the financial revenues from this model are much higher than from the others (e.g., applying new varieties of rice). Finally, this model involves smaller risks than switching to shrimp production as a result of combining fish and lotus in the same ponds. Third, the technical requirements for adaptation are not too high and match the local farmers' abilities.

Two questions remain after this AHP analysis: (1) What can be done with its outcome in central coastal region of Vietnam? (2) What are the broader implications from this study?

Obviously, our results are helpful for local authorities in the study area that want to develop a long-term strategy to cope with climate change and for local farmers in making decisions about the most suitable adaptation methods to tackle SWI. AHP has proven to provide a solid scientific basis for policy makers to rank the adaptation measures, which has never officially been done in Vietnam to date. Based on expert interviews, we found that, to date, the selection of an adaptation solution by farmers has the following sequence: local authorities (with consultations from stakeholders involved in climate change adaptation) inform and recommend which adaptation measures are suitable for natural and social and economic conditions. Then, if the budget is available, these adaptation methods will be tested locally as the demonstration models to which farmers can refer. If there is no budget, local authorities can organize field trips (with the involvement of farmers' representatives) to regions where these adaptation methods have been successfully implemented. For new adaptation measures, the authorities will provide technical assistance but, financially, the vast majority of farmers have to borrow capital to implement the project by themselves. It is important that the local authorities present suitable adaptation methods to farmers, as we found that many of them intended to apply at least one adaptation method in the next five years based on the FGDs and field observations in this project. Whether all farmers switch their activities to the most preferred adaptation method for the area in which they live remains questionable. Through FGDs and in-depth interviews, we learned that the coconut-fish and lotus-fish models are the optimal long-term adaptation methods. These methods have high demands in terms of capital and land surface, not allowing farmers to switch easily in the near future. Moreover, food security through rice production is still a dominant priority in the policies of the Vietnamese Government, so that local authorities might want to control the percentage of paddy field plots that move to new alternatives in the future. However, given the capital requirements involved in SWI adaptation, the possibility of all farmers moving to the new alternatives at the same time in the near future is nonexistent in either study area. One final issue for local authorities that came out of our research was the fact that the linkages between local authorities, agribusiness companies, and farmers are rather weak. In order to address the uncertainties that farmers face when it comes to market conditions, local authorities can facilitate the relations between farmers and agribusiness companies (e.g., by supporting contract farming through guarantees for the different parties involved). Reliable market forecasts were reported in the FGDs to be essential in this process.

On a more general level, our research has underlined once again the potential of MCA techniques (and AHP in particular) to address the complexity involved in CC adaptation. In doing so, it adds to the literature on the effectiveness of AHP to support (local) authorities in ranking alternative adaptation methods. Several elements in our research are valuable for other ranking exercises. First, the data collection process that we designed illustrates how to make optimal use of the expertise of different stakeholders involved in local agriculture processes Next, the set of components and indicators that we have developed can be used in other studies that focus specifically on SWI issues, bearing in mind differences between study regions. In the context of rising sea levels becoming increasingly serious [7], SWI is an inevitable consequence that many areas both within and beyond Vietnam will face in the near future [12]. Our study provides a starting point to help areas that have similar social and natural conditions to find the most effective adaptation measures, thereby saving time and resources. Additionally, for other regions that are suffering different impacts from 
climate change, the AHP method outlined by this paper can be considered to rank different suitable adaptation options in the design of climate change adaptation strategies.

Supplementary Materials: The following are available online at https:/ /www.mdpi.com/2071-105 0/13/4/2311/s1, Figure S1: Stakeholders involved in climate change adaption, Figure S2: Hierarchical tree, Table S1: Research applying the AHP method in adapting to CC, Table S2: Background information on the FGDs, Table S3: Table of potential indicators, Table S4: Short list of indicators, Table S5: List of 11 alternatives, Table S6: Pairwise comparison matrix of indicators with respect to A1 and A2 in Duy Xuyen district, Table S7: Pairwise comparison matrix of indicators with respect to A3 and A4 in Duy Xuyen district, Table S8. Pairwise comparison matrix of subindicators with respect to B1, B2, and B3 in Duy Xuyen District, Table S9. Pairwise comparison matrix of subindicators with respect to B4, B5, and B6 in Duy Xuyen district, Table S10. Pairwise comparison matrix of subindicators with respect to B7 and B8 in Duy Xuyen district, Table S11. Pairwise comparison matrix of subindicators with respect to B9 and B10 in Duy Xuyen district, Table S12. Pairwise comparison matrix of indicators with respect to A1 and A2 in Quang Dien district, Table S13. Pairwise comparison matrix of indicators with respect to A3 and A4 in Quang Dien district, Table S14. Pairwise comparison matrix of subindicators with respect to B1, B2, and B3 in Quang Dien district, Table S15. Pairwise comparison matrix of subindicators with respect to B4, B5, and B6 in Quang Dien district, Table S16. Pairwise comparison matrix of subindicators with respect to B7 and B8 in Quang Dien district, Table S17: Pairwise comparison matrix of subindicators with respect to B9 and B10 in Quang Dien district, Table S18: Scoring alternatives in Duy Xuyen district, Table S19: Scoring alternatives in Quang Dien district.

Author Contributions: T.D.L.N. and B.B. designed and drafting outline. T.D.L.N. collected data and drafted the manuscript. B.B. revised manuscripts. T.D.L.N. and B.B discussed the results. All authors have read and agreed to the published version of the manuscript.

Funding: This research was funded by BOF PhD Scholarship of Ghent University (80200244130530326415).

Institutional Review Board Statement: Not applicable.

Informed Consent Statement: Informed consent was obtained from all subjects involved in the study.

Data Availability Statement: All relevant study data is contained within the article and supplementary material.

Acknowledgments: Special thanks to the local authorities of two districts Duyen Xuyen and Quang Dien.

Conflicts of Interest: The authors declare no conflict of interest.

\section{References}

1. World Economic Forum. The Global Risks Report 2019, Geneve. p. 6. Available online: http:/ /wef.ch/risks2019 (accessed on 15 November 2020).

2. IPCC. Climate Change 2014: Impact, Adaption and Vulnerability; Fifth Asessment Report; IPCC: Geneva, Switzerland, $2014 ;$ p. 849.

3. McElwee, P. The Social Dimensions of Adaptation to Climate Change in Vietnam. 2010. Available online: http:/ / climatechange. worldbank.org/sites/default/ files/documents/Ghana-EACC-Social.pdf\%5Cn (accessed on 30 August 2012).

4. Shaw, R. Community-based climate change adaptation in Vietnam: Inter-linkages of environment, disaster, and human security. In Multiple Dimension of Global Environmental Changes; Sonak, S., Ed.; TERI Publication: Tokyo, Japan, 2006; pp. 521-547.

5. Yu, B.; Zhu, T.; Breisinger, C.; Hai, N.M. Impacts of Climate Change on Agriculture and Policy Options for Adaptation The Case of Vietnam, 01015, 2010. [Online]. Available online: http:/ /www.ifpri.org/publications/results/taxonomy\%3A468 (accessed on 4 February 2019).

6. Nguyen, T.T.; Bonetti, J.; Rogers, K.; Woodroffe, C.D. Indicator-based assessment of climate-change impacts on coasts: A review of concepts, methodological approaches and vulnerability indices. Ocean Coast. Manag. 2016, 123, 18-43. [CrossRef]

7. Irish Aid. Vietnam Climate Action Report; Irish Aid: Hanoi, Vietnam, 2015.

8. Thuc, T.; Neefjes, K. Viet Nam Special Report on Managing the Risks of Extreme Events and Disasters to Advance Climate Change Adaption; UNDP: Hanoi, Vietnam, 2015.

9. Van, S.; Boyd, W.; Slavich, P.; Van, T. Perception of Climate Change and Farmers' Adaptation: A Case Study of Poor and Non-Poor Farmers in Northern Central Coast of Vietnam. J. Basic Appl. Sci. 2015, 11, 323-342. [CrossRef]

10. Shrestha, S.; Deb, P.; Bui, T.T.T. Adaptation strategies for rice cultivation under climate change in Central Vietnam. Mitig. Adapt. Strat. Glob. Chang. 2014, 21, 15-37. [CrossRef] 
11. Trinh, T.Q.; Rañola, R.F.; Camacho, L.D.; Simelton, E. Determinants of farmers' adaptation to climate change in agricultural production in the central region of Vietnam. Land Use Policy 2018, 70, 224-231. [CrossRef]

12. Thuc, T.; Van Thang, N.; Huong, N.T.L.; Van Khiem, M.; Hien, N.X.; Doan, H.P. Climate Change and Sea Level Rise Scenarios for Viet Nam; MONRE: Hanoi, Vietnam, 2017; Available online: http:/ / science.sciencemag.org/content/294/5547/1617.abstract (accessed on 16 September 2019).

13. Ho, C. The Climate Change in Vietnam and its Impact on Agricultural Sector in Vietnam. In Proceedings of the 24th SESAM Annual Meeting, Bilbao, Spain, 27-29 June 2018.

14. Poudel, S.; Kotani, K. Climatic impacts on crop yield and its variability in Nepal: Do they vary across seasons and altitudes? Clim. Chang. 2012, 116, 327-355. [CrossRef]

15. Iizumi, T.; Yokozawa, M.; Nishimori, M. Probabilistic evaluation of climate change impacts on paddy rice productivity in Japan. Clim. Chang. 2010, 107, 391-415. [CrossRef]

16. Trærup, S.; Bakkegaard, R.K. Evaluating and Prioritizing Technologies for Adaptation to Climate Change-A Hands on Guidance to Multi Criteria Analysis (MCA) and the Identification and Assessment of Related Criteria; Technical University of Demark: Copehagen, Demark, 2015.

17. Berkhout, F.; Hertin, J.; Gann, D.M. Learning to Adapt: Organisational Adaptation to Climate Change Impacts. Clim. Chang. 2006, 78, 135-156. [CrossRef]

18. De Bruin, K. Ranking Climate Change Adaptation Options through Multi-Criteria Analysis The Netherlands India Decision Support Tools; NZCCRI Seminar Series; CIREO: Oslo, Norway, 2014.

19. Grafakos, S.; Olivotto, V.; Studies, U.D. Choosing the Right Adaptation Assessment Method, Resilent Cities; Insititute for Housing and Urban Development Studies, Emarus University Rotterdam: Rotterdam, The Netherlands, 12 May 2012.

20. Dixit, A.; McGRay, H. Analyzing Climate Change Adaptation Options Using Multi-Criteria Analysis; USAID: Arlington, VA, USA, 2013.

21. Saaty, T.L. The Analytic Hierarchy and Analytic Network Process for the Measurement of Intangible Criteria and for DecisionMaking. In Multiple Criteria Decision Analysis. State of the Art Surveys; Greco, S., Ed.; Springer: Berlin, Germany, 2016; pp. 363-420.

22. Forman, E.H.; Gass, S.I. The Analytic Hierarchy Process-An Exposition. Oper. Res. 2001, 49, 469-486. [CrossRef]

23. Kangas, A.; Kangas, J.; Pykäläinen, J. Outranking methods as tools in strategic natural resources planning. Silva Fenn. 2001, 35, 215-227. [CrossRef]

24. Saaty, T.L. How to Make a Decision: The Analytic Hierarchy Process. Eur. J. Oper. Res. 1990, 48, 9-26. [CrossRef]

25. Sen, L. Methods of Selecting the Solutions for Climate Change Adaption in Agricultural Production; Hue University Publisher: Hue, Vietnam, 2016.

26. Van Ierland, E.C.; Bruin, K.; De Watkiss, P. Multi_Criteria Analysis: Decision Support Methods for Climate Change Adaptation; Meditation Project: Bruselles, Belgium, 2013; Briefing Note 6.

27. Noleppa, S. Economic Approaches for Assessing Climate Change Adaptation Options under Uncertainty: Excel Tools for Cost-Benefit and Multi-Criteria Analysis; GIZ: Eschborn, Germany, 2013; p. 27.

28. Fischer, G. MCA4climate: A Practical Framework for Planning Pro- Development Climate Policies; UNEP: Nairobi, Kenya, 2011; Available online: www.mca4climate.info (accessed on 9 March 2020).

29. Chaudhary, P.; Chhetri, S.K.; Joshi, K.M.; Shrestha, B.M.; Kayastha, P. Application of an Analytic Hierarchy Process (AHP) in the GIS interface for suitable fire site selection: A case study from Kathmandu Metropolitan City, Nepal. Socio-Econ. Plan. Sci. 2016, 53, 60-71. [CrossRef]

30. Van Cauwenbergh, N.; Biala, K.; Bielders, C.; Brouckaert, V.; Franchois, L.; Cidad, V.G.; Hermy, M.; Mathijs, E.; Muys, B.; Reijnders, J.; et al. SAFE-A hierarchical framework for assessing the sustainability of agricultural systems. Agric. Ecosyst. Environ. 2007, 120, 229-242. [CrossRef]

31. Huehner, M.; Rozman, Č.; Pažek, K. A Case Study on the Application of the Analytic Hierarchy Process ( AHP ) to Assess Agri-Environmental Measures of the Rural Development Programme (RDP 2007-2013) in Slivenia. In Applications and Theory of Analytic Hierarchy Process—Decision Making for Strategic Decisions; INTECH: London, UK, 2016; pp. 38-54.

32. Ni, J.R.; Li, Y.K. Approach to soil erosion assessment in terms of land-use structure changes. J. Soil Water Conserv. 2003, 58, 158-169.

33. Ramanathan, R.; Ganesh, L. Energy resource allocation incorporating qualitative and quantitative criteria: An integrated model using goal programming and AHP. Socio-Econ. Plan. Sci. 1995, 29, 197-218. [CrossRef]

34. Tran, T.X.M.; Malano, H.; Thompson, R.G. Application of the analytic hierarchy process to prioritise irrigation asset renewals: The case of the La Khe irrigation scheme, Vietnam. Eng. Constr. Arch. Manag. 2003, 10, 382-390. [CrossRef]

35. Singpurwalla, N.; Forman, E.; Zalkind, D. Promoting shared health care decision making using the analytic hierarchy process. Socio-Econ. Plan. Sci. 1999, 33, 277-299. [CrossRef]

36. Wasil, E.; Golden, B.L. Introduction: Public-sector applications of the analytic hierarchy process. Socio-Econ. Plann. Sci. 1991, 25, 87-88. [CrossRef]

37. Macharis, C.; Springael, J.; De Brucker, K.; Verbeke, A. PROMETHEE and AHP: The design of operational synergies in multicriteria analysis. Eur. J. Oper. Res. 2004, 153, 307-317. [CrossRef]

38. Ramanathan, R. A note on the use of the analytic hierarchy process for environmental impact assessment. J. Environ. Manag. 2001, 63, 27-35. [CrossRef] 
39. Samari, D.; Azadi, H.; Zarafshani, K.; Hosseininia, G.; Witlox, F. Determining appropriate forestry extension model: Application of AHP in the Zagros area, Iran. For. Policy Econ. 2012, 15, 91-97. [CrossRef]

40. Velasquez, M.; Hester, P. An analysis of multi-criteria decision making methods. Int. J. Oper. Res. 2013, 10, 56-66.

41. Quang Dien People Committee. Annual Report of Agricultural and Rural Development of Quang Dien District; QDPC: Thua Thien Hue, Vietnam, 2019.

42. Duy Xuyen People Committee. Annual Report of Agricultural and Rural Development of Duy Xuyen District; DXPC: Quang Nam, Vietnam, 2019.

43. Hanley, N.; Owen, A.D. The Economics of Climate Change. Econ. Clim. Chang. 2004, 98, 1-37. [CrossRef]

44. Weiland, S.; Troltzsch, J.; Capriolo, A.; Den Uyl, R.; Jensen, A.; Giordana, F.; Hidén, M.; Karali, E.; Mäkinen, K.; Nielsen, H.; et al. BASE Evaluation Criteria for Climate Adaptation (BECCA). 2015. Available online: http://base-adaptation.eu/sites/default/ files/BASE_Policy_3_June_2015_0.pdf (accessed on 20 November 2019).

45. Yohe, G.; Tol, R.S. Indicators for social and economic coping capacity-moving toward a working definition of adaptive capacity. Glob. Environ. Chang. 2002, 12, 25-40. [CrossRef]

46. Adger, W.N.; Arnell, N.W.; Tompkins, E.L. Successful adaptation to climate change across scales. Glob. Environ. Chang. 2005, 15, 77-86. [CrossRef]

47. Brooks, N.; Anderson, S.; Ayers, J.; Burton, I.; Tellam, I. Tracking Adaptation and Measuring Development; IIED Climate Change Working Paper no. 1; International Institute for Environment and Development: London, UK, 2011.

48. Bosello, F.; Carraro, C.; De Cian, E. An Analysis of Adaptation as a Response to Climate Change; No,26/Wp/2009; University Ca'Foscari of Venice: Venice, Italy, 2009.

49. Greco, S.; Ehrgott, M. Multiple Criteria Decision Analysis. State of the Art Surveys, 2nd ed.; Figueira, J.R., Ed.; Springer: Berlin, Germany, 2016; pp. 363-420.

50. Mu, E.; Pereyra-Rojas, M. Understanding the Analytic Hierarchy Process. In Pratical Decision Making. An introduction to the Analytic Hierarchy Process (AHP); Springer: Berlin, Germany, 2017; pp. 7-22. 